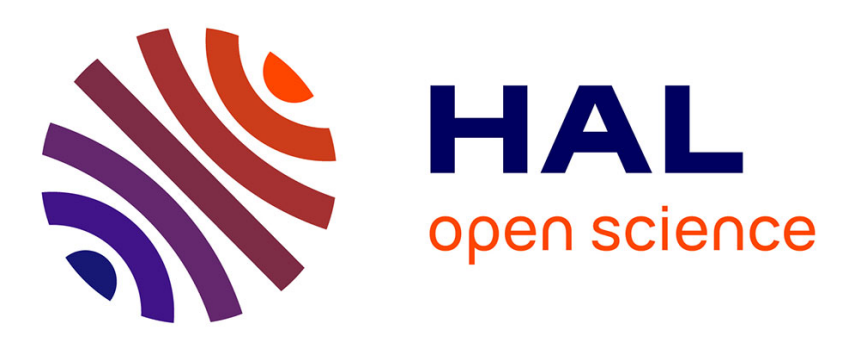

\title{
What criteria affect a patient's choice of catheter for self-catheterization?
}

Claire Hentzen, Nicolas Turmel, Camille Chesnel, Gabriel Miget, Frédérique Le Breton, Audrey Charlanes, Eliane Tan, Gérard Amarenco

\section{To cite this version:}

Claire Hentzen, Nicolas Turmel, Camille Chesnel, Gabriel Miget, Frédérique Le Breton, et al.. What criteria affect a patient's choice of catheter for self-catheterization?. Neurourology and Urodynamics, 2019, 39 (1), pp.412-419. 10.1002/nau.24223 . hal-02485658

\section{HAL Id: hal-02485658 \\ https://hal.sorbonne-universite.fr/hal-02485658}

Submitted on 20 Feb 2020

HAL is a multi-disciplinary open access archive for the deposit and dissemination of scientific research documents, whether they are published or not. The documents may come from teaching and research institutions in France or abroad, or from public or private research centers.
L'archive ouverte pluridisciplinaire HAL, est destinée au dépôt et à la diffusion de documents scientifiques de niveau recherche, publiés ou non, émanant des établissements d'enseignement et de recherche français ou étrangers, des laboratoires publics ou privés. 
What Criteria Affect a Patient's Choice of Catheter for Self-Catheterization?

C. Hentzen ${ }^{1}$ M.D., N. Turmel ${ }^{1}$ M.D., C. Chesnel ${ }^{1}$ M.D., G. Miget ${ }^{1}$ M.D., F. Le Breton ${ }^{1}$ M.D., A. Charlanes ${ }^{1}$ M.D., E. $\operatorname{Tan}^{1}$ Mrs, G. Amarenco ${ }^{1}$ Ph.D.

${ }^{1}$ Sorbonne Université, GRC 001, GREEN Groupe de Recherche Clinique en Neuro-Urologie, AP-HP, Hôpital Tenon, F-75020 Paris, France

\section{Abstract}

Aims: The aim was to determine which criteria are most influential in guiding the patient's choice of catheter during clean intermittent self-catheterization (CISC) education.

Methods: a questionnaire exploring five traits (catheter design, catheter length, comfort of use, nurse's explanations, and how easy it was to carry and dispose of the catheter) was administered to all patients who succeeded in performing CISC. The patients had to report the criterion that most influenced their choice, and rate the importance of each criterion from 1-4 on a Likert scale (strongly disagree, somewhat disagree, somewhat agree, strongly agree). The study assessed the impact that age, sex, etiology, dependency, motor or sensory upper limbs deficiency and position required to perform CISC may have had on the importance of the different criteria.

Results: Seventy-three patients were included (mean age $50.9 \pm 14.3$ years). The most important criterion was the nurse's explanations (44\%), followed by comfort of handling (32\%), the discreet aspect of carrying the catheter (15\%), catheter length (7\%). The esthetic aspect was not important for $34 \%$ of patients, whereas all the other criteria were important for at least $82 \%$ of patients. Comfort of handling was more often a priority for those with motor or sensory upper limbs disorder $(p<0.01)$. The other characteristics of the patients did not impact the way they prioritized the criteria. 
Conclusion: These results highlight the importance of extensive training for nurses involved in CISC education, as their explanations have the greatest impact on the patient's choice of catheter.

Keywords: Intermittent Urethral Catheterization; Patient Preference; Patient Education as Topic; Teaching; Nurses; Urinary Retention; Urinary Bladder, Neurogenic

Registered on clinicaltrials.gov: NCT04033913 


\section{Introduction}

Clean intermittent self-catheterization (CISC) was introduced by Lapides et al in $1972^{1}$. Nowadays, it is the gold standard for the treatment of urinary retention in neurogenic bladders and is being proposed more and more often to patients with non-neurogenic lower urinary tract symptoms (LUTS). Several studies have demonstrated an improvement in the quality of life of patients using $\mathrm{ClSC}^{2,3}$. The availability of hydrophilic and self-lubricating catheters has reduced traumatic and infectious complications and compact catheters have contributed to improved quality of life, allowing smoother integration of CISC into the patient's social and work life ${ }^{4}$. Some studies have been conducted to explore factors limiting CISC, whether difficulties learning or in continued use. These studies found that obesity, being female, or having motor or cognitive disorders have a negative impact on the ability to learn $\mathrm{CISC}^{5-7}$, and older age, important stress urinary incontinence, and dependency for CISC installation were predictive for a poorer adherence to the method ${ }^{8,9}$.

Aseptic or clean intermittent catheterizations are taught to patients, with no evidence of the superiority of one over the other in terms of occurrence of complications. Guidelines on technique differ according to scientific societies. Teaching self-catheterization is now well established, and various nursing journals describe the different steps of the CISC educational $\operatorname{program}^{10}$. However, no studies have shown the benefit of these programs on successful learning or adherence ${ }^{11}$. Many psychological barriers can limit the practice of $\mathrm{CISC}^{12}$ but the main challenge is to obtain the patient's acceptance and long-term adherence to CISC, as urinary disorders are mostly chronic, and sometimes involve a risk of damage to the upper urinary tract specially in neurogenic patients like those with spinal cord injuries and multiple sclerosis. 
Currently there are many catheter models available. The choice may depend on different factors: grip disorder, ease of use, design and packaging, discomfort or pain when testing a specific material, specific anatomical conditions (male Tiemann or olive tip), longer catheter length in case of imperfect emptying, explanations given on how to use the catheter, etc. While the doctor and nurse involved in the patient's therapeutic education guide the choice of catheter according to medical criteria and the patient's physical capacities (despite the lack of objective and randomized studies for many criteria), the patient remains an active participant in the choice of model. Indeed, being involved in this process could encourage adherence to the treatment.

The primary aim of this study was to evaluate which criteria are most important to the patient when choosing a catheter. The secondary aim was to assess whether the individual characteristics of the patient changed the importance he or she attached to each criterion.

\section{Methods}

\subsection{Study design}

This study was approved by the local ethics review board, registration number 2018-A0164451, and all participants provided written informed consent before inclusion in this observational study. This study was registered on clinicaltrials.gov: NCT04033913. Participants were recruited in the Neuro-urology department, the day they came to learn to perform CISC (educational program).

\subsection{Participants}

Inclusion criteria were: adult patients who have successfully perform self-catheterization during the educational program in the Neuro-urology department. Exclusion criteria were only refusal to participate. Participants were recruited between November 2018 and August 
2019. Patients were included and completed the questionnaire on the day of the CISC training, so they had not yet tried CISC in their daily life.

\subsection{Procedure}

The questionnaire was developed based on meetings with experts and reviewing literature about what factors may contribute to patient satisfaction with their self-catheterization device. The panel of experts was composed of 7 doctors specialized in neuro-urology, 3 nurses with significant experience in CISC therapeutic education, one occupational therapist and one neuropsychologist involved in therapeutic education. Based on literature review, 7 criteria were singled out: "design of the catheter", "packaging appearance", "length of the catheter", "comfort handling the catheter", "comfort introducing the catheter", "nurse's explanations", "easy to wear and dispose of the catheter". Based on clinical experience, the criterion "comfort when introducing the catheter" was eliminated because the majority of patients try only one type of catheter after handling several, and therefore cannot compare comfort when introducing it into the urethra between several models. The experts also decided to combine the design of the catheter and the appearance of the packaging into a single criterion "catheter and packaging design"; the two criteria seem too similar to be distinguished.

Five factors were therefore finally selected: "catheter and packaging design", "catheter length", "comfort using the catheter", "nurse's explanations", "easy to carry and dispose of the catheter".

This led to a short questionnaire with 5 questions:

- Position in which CISC was performed (toilet, wheelchair, bed)

- Number of types of catheter showed during therapeutic education

- Importance of the different factors in the choice of catheter 
- Number of types of catheter tried during the therapeutic education

- Choice of catheter (the first one tried, the second one, two different types, other)

The importance of each criterion was rated from 1-4 on a Likert scale (strongly disagree, somewhat disagree, somewhat agree, strongly agree), and each patient had to report the most important criterion in the choice of the catheter. In this case, there was no need for a neutral mid-point on the scale because the question was not about satisfaction with a criterion, but about its importance in the patient's choice. Thus, a neutral mid-point was irrelevant.

Nurses gave the questionnaire at the end of the training. Demographic data was collected (age, sex, etiology of urinary disorders) and some functional scores were taken during therapeutic education to assess dependency (Functional Independence Measure (FIM) score ${ }^{13}$ ), sensory-motor functions in the upper limbs (Motor hand disorders assessed by a Nine Hold Peg Test ${ }^{14}$ over 18 , sensory hand disorders assessed by Weber compass and clinical examination), and CISC skills (Pencil and Paper Test ${ }^{15}$, maximum score of 15)

\subsection{Statistical analysis}

Statistical analyses were performed with the $R$ software for Windows (Rx64 3.2.3, R Foundation for Statistical Computing, Vienna, Austria). Descriptive data were presented as means with standard deviation for continuous data and as medians with range for ordinal data and data not normally distributed. For secondary analyses, the responses "strongly disagree" and "somewhat disagree" were pooled into "disagree", and the responses "strongly agree" and "somewhat agree" into "agree" to identify associations with patients' characteristics. The association between patient characteristics and the choice of priority criterion was studied only for the 2 criteria most commonly identified as the most important. 
The impact of age, sex, etiology, score on the Pencil and Paper Test, dependency, motor or sensory deficit of the upper limbs, and the position in which CISC was performed on the importance of the different criteria was assessed using Welch's t-test and the Fisher Test. Significance was taken as $p<0.05$.

3. Results

\subsection{Patients characteristics}

Seventy-three patients were included, with a mean age of $50.9 \pm 14.3$ years. Patient characteristics are provided in Table 1 . The majority of patients (89\%) learned to perform CISC on the toilet (sitting or standing), 5.5\% learned in a wheelchair and $5.5 \%$ in a bed. The majority of patients (97\%) had seen at least two models of catheter, on average $2.8 \pm 1.2$ were shown. Forty-six (63\%) patients tried at least two different models of catheter. Forty-five patients (62\%) chose the first model they tried, $18(25 \%)$ the second one, $5(7 \%)$ two models to adapt to their activities.

Fifty-nine patients fully completed the questionnaire and 14 patients did not choose a most important criterion. All the other questions were completed.

\subsection{Most important criterion in catheter choice}

The most important criterion for the final choice of catheter was the nurse's explanations (44\%), followed by the comfort of handling the catheter (32\%). The discreet aspect of transport and disposal was a priority for $15 \%$ of patients, the length of the catheter for $7 \%$, and the esthetic aspect only for 1 patient (2\%). Results are summarized in Figure 1 . Patients who did not answer this question were not different from those who completed the entire 
questionnaire, except at a lower mean age (44.2 \pm 12.1 vs $52.5 \pm 14.4, p=0.04)$. The comparison of the two groups is reported in Table 4 in supporting information.

\subsection{Importance of each criterion}

The way the catheter looked (design) was not important to $34 \%$ of patients, whereas all the other criteria were important for at least $82 \%$ of them. The nurse's explanations were the only criterion of unanimous importance. All the answers are reported in Figure 2.

\subsection{Impact of patient characteristics on the criterion they prioritized}

The comfort of handling the catheter was more often a priority for patients with sensory and/or motor deficits in the upper limbs $(p<0.01)$. Age, sex, etiology of LUTS, Pencil and Paper Test fewer than 15, FIM score and position in which CISC was performed did not impact the choice of patients' prime criterion. All results are reported in Table 2 .

\subsection{Impact of patient characteristics on the importance of each criterion} Women were more likely to attach importance to catheter and packaging design than men $(p=0.03)$. In contrast, patients who catheterized themselves in bed or in a wheelchair gave less importance to this criterion $(p=0.02)$. Catheter length was important for $88 \%$ of women and only $60 \%$ of men $(p=0.03)$.

Concerning the criterion "easy to carry and dispose of the catheter", the number of different catheters seen were higher for patients who considered this criterion to be important $(2.3 \pm$ 0.9 vs. $2.9 \pm 1.2 ; p=0.04)$.

Other patient characteristics did not influence the importance given to each criterion. All the results are reported in Table 3. 



\section{Discussion}

Our study shows that in general all the criteria studied are important in the patient's choice of catheter. Discrete transportation and disposal are more important than the design of the catheter. The most important criterion is the nurse's explanations, followed by ease of use and handling, especially for patients with sensory and/or motor deficits of the upper limbs. These results are not surprising since the different criteria mentioned are those explored in the questionnaire InCaSaQ on catheter satisfaction, defined on the basis of an open-ended interview with patients who performed $\mathrm{CISC}^{16}$. Nurse's explanations were often cited as the most important criterion. There is potentially a bias in these responses; the questionnaire was given by the nurse at the end of the training, and the patient might want to please the nurse/doctor with his or her answer. However, there are several other explanations for this choice. First of all, the nurse is a healthcare professional, specifically trained to provide therapeutic $\mathrm{CISC}$ education. He/she has specific knowledge that allows him/her to sum up the pros and cons of each type of catheter. Secondly, patients are unfamiliar with CISC so they rely on the person who has the expertise. Logan et al $^{17}$ reported with patient interviews how learning CISC can be stressful and embarrassing. Nurses' attitudes, including a friendly relationship and sufficient explanations are one of the main elements that promote a positive experience in CISC therapeutic education. In our study, of the 30 patients who left a free-form comment, 11 thanked or highlighted the nurse's professionalism.

The need for easy use has been described by Denys et al ${ }^{18}$ as a factor that can lead patients using $\mathrm{CISC}$ to change their catheter type. It seems natural that when learning a new technique that may be quite stressful, an easy-to-handle catheter should be an important criterion. The importance of discretion when carrying and disposing of the catheter was evoked by Jaquet et $\mathrm{al}^{19}$ as paramount for patients who had been performing CISC for at 
least 6 months. Patients reported the importance of being able to hide the catheter in public places and they did not mention CISC at work, reflecting their desire for the discreet social integration of their CISC device.

Women attached more importance than men to esthetics and more surprisingly to the length of the probe. One possible explanation is that male catheters are all relatively long, because of the length of the male urethra, while women may be "pleasantly surprised" when they discover that female catheters are relatively short, far from the image of indwelling catheters that they might be familiar with. The impact of enlarged prostate on catheter choice was not studied because among the men included, 4 had prostate hyperplasia diagnosed with ultrasonography, but this obstruction was not the cause of urinary disorders for any of them (detrusor underactivity or detrusor sphincter dyssynergia).

This study is one of the only ones interested in the patient's perception of the different types of catheters during therapeutic education with a large sample. The interest is multiple; at present, the choice of catheter models is so vast that it is inevitable that the patient's choice be taken into account. The patient's participation in this choice makes him/her an "actor" in his/her treatment, and could promote adherence to CISC. In cases of multiple sclerosis, the American Association of Neurology recommends at a grade A level incorporating patient preference in the choice of "disease modifying therapy", suggesting that taking into account patient preferences may improve acceptance of and adherence to "disease modifying therapy" ${ }^{20}$. The concept of "shared decision-making" has been expanding for several years in the treatment of chronic diseases. It is a process in which the physician elicits the patient's values and preferences about their care, has an evidence-based discussion of treatment options, and allows for a common treatment decision to be reached ${ }^{21}$. This approach showed several benefits in patient satisfaction and knowledge. The positive influence on 
adherence is less systematic and has been demonstrated in hypertension ${ }^{22}$ and asthma ${ }^{23}$ but not yet in neurological diseases such as multiple sclerosis ${ }^{21,24}$ nor in neuro-urology. Better knowledge of which criteria are important to the patient can improve therapeutic education, but also provide a guide for the criteria to be met in the creation of new catheter models.

This study has several limitations. First, the questionnaire used is not validated but was the result of an expert consensus. Secondly "nurse's explanations" are a variable factor, depending on the habits, experience, preferences and perceptions of each healthcare professional. The presentation of the catheters will generally be adapted to each patient, depending on the transference and counter-transference of the situation. However, all the nurses participating in this session were very experienced with over 4 years of clinical practice in teaching CISC. Another limitation is the heterogeneity of the population, with a majority of women $(79 \%)$ and neurologic patients $(89 \%)$. But this probably reflects the population affected by $\mathrm{CISC}$ whose main indication is neurological urinary retention, with a large prevalence of multiple sclerosis. The answers obtained are subjective and can probably also be influenced by factors other than those tested (patient's environment, psychological state, duration of follow-up in the department).

Different perspectives exist. The importance given to the nurse's message supports the need for learning CISC during a standardized therapeutic education program. Oh et $\mathrm{al}^{25}$ reported greater patient satisfaction when CISC was learned during a specific and standardized program, with better understanding and assimilation of the provided information. The explanations should allow the patient to choose the catheter best suited to his/her physical abilities and daily activities. It would be interesting to explore the long-term satisfaction (weeks, months, years) of patients with the catheter they chose based on the most important criterion in their choice. Even more than patient training and information, this 
study highlights the need for specific and detailed training of the nurses involved in therapeutic education programs. It is essential that they have a good understanding of the different characteristics of the catheters, and can present their advantages and disadvantages, without being influenced by the marketing arguments put forward by sales representatives.

\section{Conclusion}

A patient's choice of catheter type is strongly influenced by the explanations given by the nurse during therapeutic education. Comfort in handling is the second most important criterion. More important than the esthetics of the packaging and the catheter, is its ability to be carried discreetly and integrated into the patient's social life. These results highlight the importance of extensive training for nurses involved in CISC therapeutic education programs. 
Table 1: Characteristics of study participants

LUTS: Lower urinary tract symptoms

Sd: standard deviation

\begin{tabular}{lr}
\hline Participants & \\
\hline Age, years \pm sd & $50.9 \pm 14.3$ \\
Gender & $58(79 \%)$ \\
Female & $15(21 \%)$ \\
Male & \\
Neurologic etiology of LUTS & \\
Central & $40(58 \%)$ \\
Peripheral & $16(23 \%)$ \\
Etiology & \\
Multiple sclerosis & $27(37 \%)$ \\
Spinal cord injury & $6(8 \%)$ \\
Cauda equina syndrome or neuropathy & $14(19 \%)$ \\
Neurological - others & $7(10 \%)$ \\
Non neurological & $11(15 \%)$ \\
Not determined & $8(11 \%)$ \\
Number of catheter models shown, mean \pm sd & $2.8 \pm 1.2$ \\
Pencil and Paper Test (median, range) & $15[11-15]$ \\
Sensory and/or motor hand disorders & $35(48 \%)$ \\
Functional Independence Measure score (median, range) & $105[68-126]$ \\
\hline
\end{tabular}


Table 2: Impact of patient characteristics on their priority criterion

Only the results for the two designated priority criteria are represented

LUTS: Lower urinary tract symptoms; sd: standard deviation; FIM: Functional Independence Measure; Priority: criterion identified as the most important for the choice of the catheter of the 5 proposed; Not: Another criterion identified as the most important

\begin{tabular}{|c|c|c|c|c|c|c|}
\hline & \multicolumn{3}{|c|}{ Comfort of using the catheter } & \multicolumn{3}{|c|}{ Nurse's explanations } \\
\hline & $\begin{array}{r}\text { Priority } \\
\mathrm{n}=19\end{array}$ & $\begin{array}{r}\text { Not } \\
n=40\end{array}$ & $\mathrm{p}$ & $\begin{array}{r}\text { Priority } \\
\mathrm{n}=26\end{array}$ & $\begin{array}{r}\text { Not } \\
\mathrm{n}=33\end{array}$ & $\mathrm{p}$ \\
\hline Gender & & & & & & \\
\hline Female & $16(84 \%)$ & $32(80 \%)$ & 1 & $20(77 \%)$ & $28(85 \%)$ & 0.52 \\
\hline Male & $3(16 \%)$ & $8(20 \%)$ & & $6(23 \%)$ & $5(15 \%)$ & \\
\hline \multicolumn{7}{|l|}{ Etiology of LUTS } \\
\hline Non-neurological & $2(11 \%)$ & $10(27 \%)$ & 0.40 & $8(31 \%)$ & $4(13 \%)$ & 0.07 \\
\hline N. central & $12(67 \%)$ & $20(54 \%)$ & & $16(61 \%)$ & $17(57 \%)$ & \\
\hline N. peripherical & $4(22 \%)$ & $7(19 \%)$ & & $2(8 \%)$ & $9(30 \%)$ & \\
\hline \multicolumn{7}{|c|}{ Sensory or motor hand disorder } \\
\hline Yes & $13(72 \%)$ & $12(33 \%)$ & $<0.01$ & $10(42 \%)$ & $15(50 \%)$ & 0.60 \\
\hline No & $5(28 \%)$ & $24(67 \%)$ & & $14(58 \%)$ & $15(50 \%)$ & \\
\hline \multicolumn{7}{|l|}{ Pencil and Paper Test } \\
\hline 15 & $14(82 \%)$ & $28(74 \%)$ & 0.74 & $16(67 \%)$ & $26(84 \%)$ & 0.21 \\
\hline$<15$ & $3(18 \%)$ & $10(26 \%)$ & & $8(33 \%)$ & $5(16 \%)$ & \\
\hline \multicolumn{7}{|l|}{ Position } \\
\hline On the toilets & $17(90 \%)$ & 37 (92\%) & 0.80 & $23(88 \%)$ & $31(94 \%)$ & 0.79 \\
\hline Wheelchair & $1(5 \%)$ & $1(3 \%)$ & & $1(4 \%)$ & $1(3 \%)$ & \\
\hline Bed & $1(5 \%)$ & $2(5 \%)$ & & $2(8 \%)$ & $1(3 \%)$ & \\
\hline $\begin{array}{l}\text { Age } \\
(\text { mean } \pm \mathrm{sd})\end{array}$ & $55.3 \pm 14.5$ & $51.2 \pm 14.3$ & 0.32 & $54.5 \pm 12.7$ & $50.9 \pm 15.6$ & 0.34 \\
\hline $\begin{array}{l}\text { Number of catheters seen } \\
(\text { mean } \pm \mathrm{sd})\end{array}$ & $2.9 \pm 1.2$ & $2.8 \pm 1.1$ & 0.74 & $2.7 \pm 1.2$ & $2.9 \pm 1.1$ & 0.48 \\
\hline $\begin{array}{l}\text { FIM score } \\
(\text { mean } \pm \text { sd })\end{array}$ & $103.0 \pm 10.8$ & $104.9 \pm 13.0$ & 0.61 & $103.6 \pm 13.8$ & $105.0 \pm 10.9$ & 0.71 \\
\hline
\end{tabular}




\section{Table 3: Impact of patient characteristics on the importance of each criterion}

The criterion "nurse's explanations" is not mentioned since all patients considered it important

LUTS: Lower urinary tract symptoms; sd: standard deviation; FIM: Functional Independence Measure; N. central: Neurological central; N. peripheral: Neurological peripheral; Imp: Important criterion for the choice, corresponding to pooled responses "strongly agree" and "somewhat agree"; Not imp: Criterion not important for the choice, corresponding to pooled responses "strongly disagree" and "somewhat disagree"

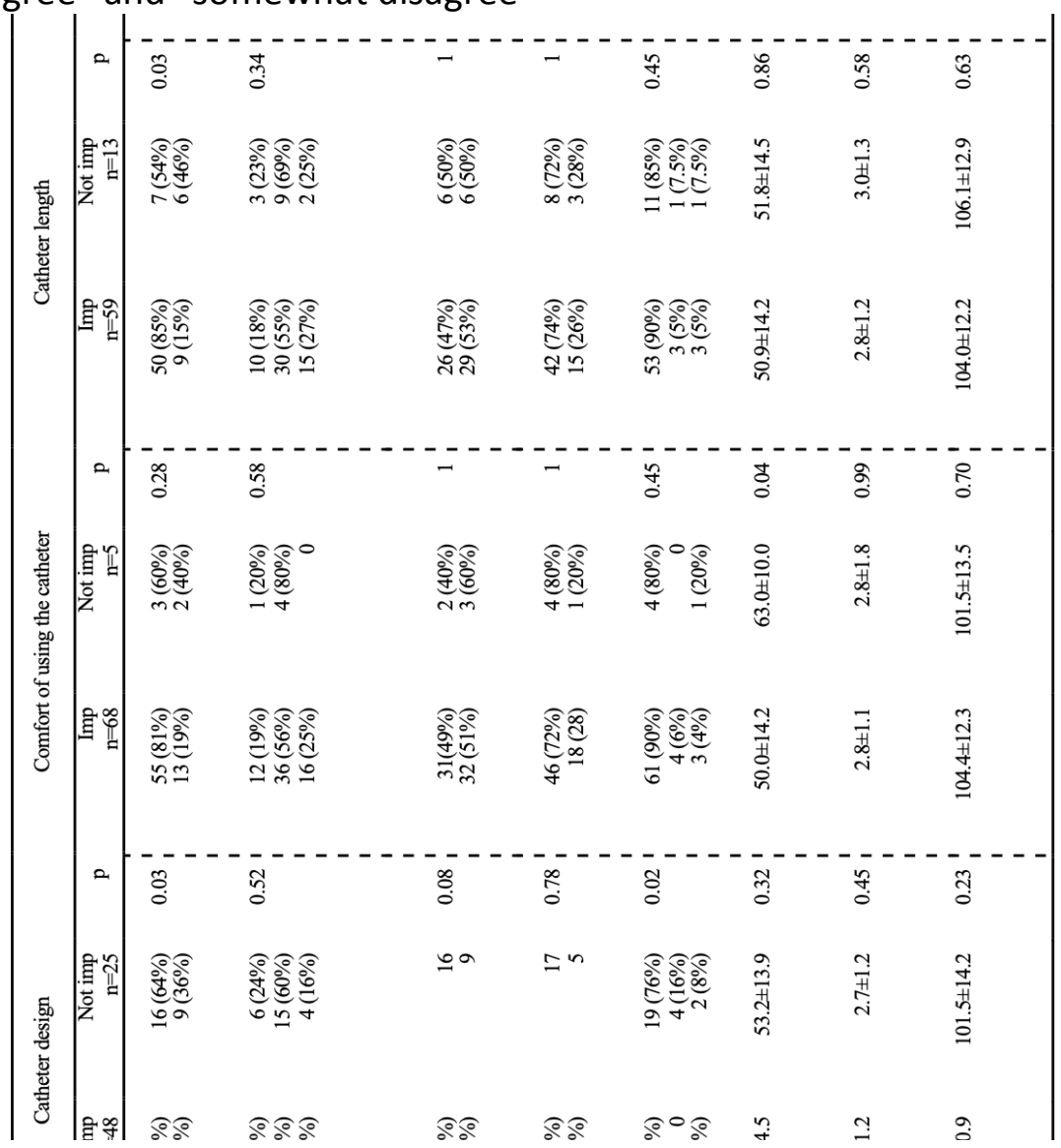


Figure 1: Most important criterion in the choice of catheter designated by each patient

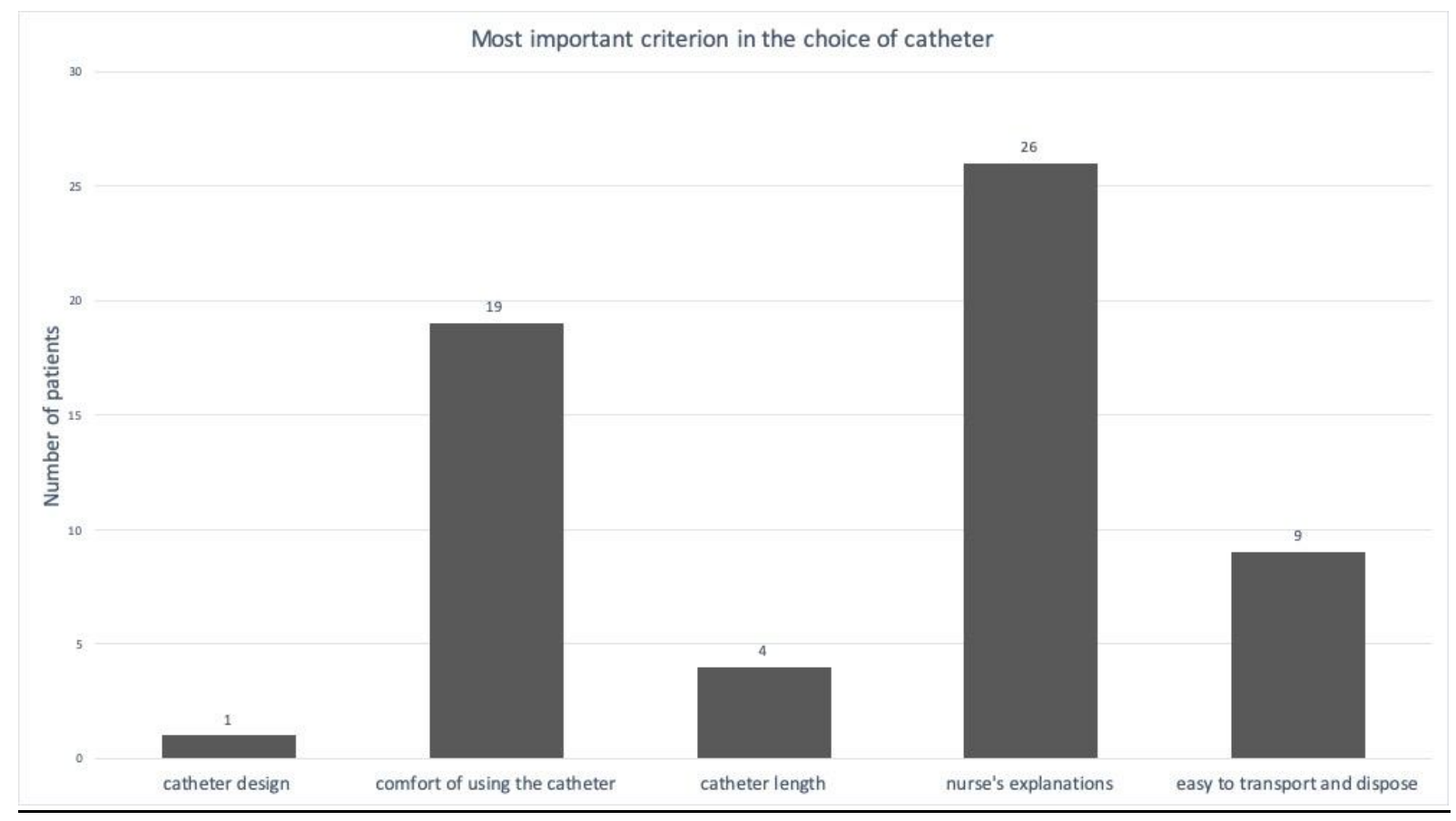


Figure 2: Importance of each criterion on a 4-level Likert scale

Importance of each criterion

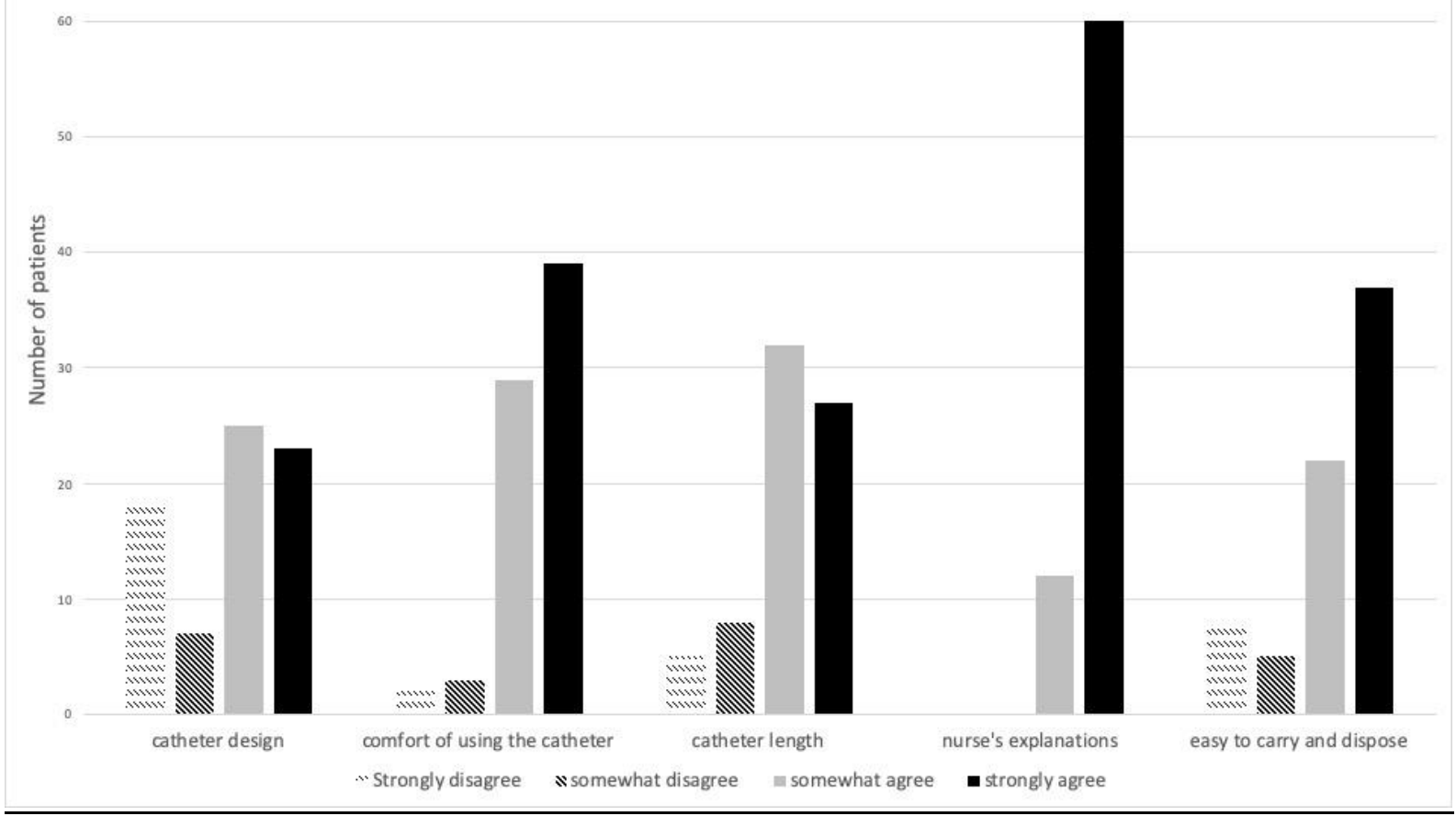


Supporting information:

\section{Table 4: Comparison of patient who completed the questionnaire fully or not}

LUTS: Lower urinary tract symptoms

Sd: standard deviation

FIM: Functional Independence Measure score

\begin{tabular}{lrrr}
\hline & $\begin{array}{r}\text { Completed } \\
\text { questionnaire } \\
\mathrm{n}=59\end{array}$ & $\begin{array}{r}\text { Not completed } \\
\text { questionnaire } \\
\mathrm{n}=14\end{array}$ & $\mathrm{p}$ \\
\hline Gender & & & \\
$\quad$ Male & $11(19 \%)$ & $4(29 \%)$ & 0.46 \\
$\quad$ Female & $48(81 \%)$ & $10(71 \%)$ & \\
Age (mean \pm sd) & $52.5 \pm 14.4$ & $44.2 \pm 12.1$ & 0.04 \\
Neurologic etiology of LUTS & & & \\
$\quad$ Central & $33(59 \%)$ & $7(54 \%)$ & 0.31 \\
$\quad$ Peripheral & $11(20 \%)$ & $5(38 \%)$ & \\
PP test 15 & $42(71 \%)$ & $8(57 \%)$ & 0.19 \\
Motor and/or sensory disorders & $29(49 \%)$ & $8(57 \%)$ & 0.55 \\
FIM (mean \pm sd) & $104 \pm 12$ & $104 \pm 13$ & 0.94 \\
Number of catheters seen (mean \pm sd) & $2.8 \pm 1.1$ & $2.9 \pm 1.4$ & 0.91 \\
\hline
\end{tabular}




\section{References:}

1. Lapides J, Diokno AC, Silber SJ, Lowe BS. Clean, intermittent self-catheterization in the treatment of urinary tract disease. J Urol. 1972;107(3):458-461.

2. Bjerklund Johansen T, Hultling C, Madersbacher H, Del Popolo G, Amarenco G. A Novel Product for Intermittent Catheterisation: Its Impact on Compliance with Daily LifeInternational Multicentre Study. Eur Urol. 2007;52(1):213-220. doi:10.1016/j.eururo.2006.11.041

3. Bakke A, Malt UF. Social functioning and general well-being in patients treated with clean intermittent catheterization. J Psychosom Res. 1993;37(4):371-380.

4. Chartier-Kastler E, Amarenco G, Lindbo L, et al. A prospective, randomized, crossover, multicenter study comparing quality of life using compact versus standard catheters for intermittent self-catheterization. J Urol. 2013;190(3):942-947. doi:10.1016/j.juro.2013.04.026

5. Vahter L, Zopp I, Kreegipuu M, Kool P, Talvik T, Gross-Paju K. Clean intermittent selfcatheterization in persons with multiple sclerosis: The influence of cognitive dysfunction. Mult Scler. 2009;15(3):379-384. doi:10.1177/1352458508098599

6. Castillo J, Ostermaier KK, Fremion E, et al. Urologic self-management through intermittent self-catheterization among individuals with spina bifida: A journey to selfefficacy and autonomy. J Pediatr Rehabil Med. 2017;10(3-4):219-226. doi:10.3233/PRM-170447

7. Hentzen C, Haddad R, Ismael SS, et al. Intermittent Self-catheterization in Older Adults: Predictors of Success for Technique Learning. Int Neurourol J. 2018;22(1):65-71. doi:10.5213/inj.1835008.504

8. Afsar SI, Yemisci OU, Cosar SNS, Cetin N. Compliance with clean intermittent catheterization in spinal cord injury patients: A long-term follow-up study. Spinal Cord. 2013;51(8):645-649. doi:10.1038/sc.2013.46

9. Hentzen C, Haddad R, Ismael SS, et al. Predictive factors of adherence to urinary selfcatheterization in older adults. Neurourol Urodyn. 2019;38(2):770-778. doi:10.1002/nau.23915

10. Mangnall J. Managing and teaching intermittent catheterisation. Br J Community Nurs. 2015;20(2):82, 84, 86, passim. doi:10.12968/bjcn.2015.20.2.82

11. Le Breton F, Guinet A, Verollet D, Jousse M, Amarenco G. Therapeutic education and intermittent self-catheterization: Recommendations for an educational program and a literature review. Ann Phys Rehabil Med. 2012;55(3):201-212. doi:10.1016/j.rehab.2012.01.006

12. Guinet-Lacoste A, Kerdraon J, Rousseau A, et al. Intermittent catheterization acceptance test (I-CAT): A tool to evaluate the global acceptance to practice clean 
intermittent self-catheterization. Neurourol Urodyn. January 2017. doi:10.1002/nau.23195

13. Ottenbacher $\mathrm{KJ}, \mathrm{Hsu} \mathrm{Y}$, Granger $\mathrm{CV}$, Fiedler RC. The reliability of the functional independence measure: A quantitative review. Arch Phys Med Rehabil. 1996;77(12):1226-1232.

14. Hervault M, Balto JM, Hubbard EA, Motl RW. Reliability, precision, and clinically important change of the Nine-Hole Peg Test in individuals with multiple sclerosis. Int J Rehabil Res Int Z Rehabil Rev Int Rech Readaptation. 2017;40(1):91-93. doi:10.1097/MRR.0000000000000209

15. Amarenco G, Guinet A, Jousse M, Verollet D, Ismael SS. Pencil and Paper Test: A New Tool to Predict the Ability of Neurological Patients to Practice Clean Intermittent SelfCatheterization. J Urol. 2011;185(2):578-582. doi:10.1016/j.juro.2010.09.106

16. Guinet-Lacoste $A$, Jousse $M$, Verollet $D$, et al. Validation of the InCaSaQ, a new tool for the evaluation of patient satisfaction with clean intermittent self-catheterization. Ann Phys Rehabil Med. 2014;57(3):159-168. doi:10.1016/j.rehab.2014.02.007

17. Logan K, Shaw C, Webber I, Samuel S, Broome L. Patients' experiences of learning clean intermittent self-catheterization: A qualitative study. J Adv Nurs. 2008;62(1):32-40. doi:10.1111/j.1365-2648.2007.04536.x

18. Denys $P$, Prévinaire JG, Aegerter $P$, de Sèze $M$, Karsenty $G$, Amarenco G. Intermittent self-catheterization habits and opinion on aseptic VaPro catheter in French neurogenic bladder population. Spinal Cord. 2012;50(11):853-858. doi:10.1038/sc.2012.68

19. Jaquet A, Eiskjaer J, Steffensen K, Laursen BS. Coping with clean intermittent catherizationâ?"Experiences from a patient perspective. Scand J Caring Sci. 2009;23(4):660-666. doi:10.1111/j.1471-6712.2008.00657.x

20. Rae-Grant A, Day GS, Marrie RA, et al. Practice guideline recommendations summary: Disease-modifying therapies for adults with multiple sclerosis: Report of the Guideline Development, Dissemination, and Implementation Subcommittee of the American Academy of Neurology. Neurology. 2018;90(17):777-788. doi:10.1212/WNL.0000000000005347

21. Colligan E, Metzler A, Tiryaki E. Shared decision-making in multiple sclerosis. Mult Scler Houndmills Basingstoke Engl. 2017;23(2):185-190. doi:10.1177/1352458516671204

22. Schoenthaler A, Rosenthal DM, Butler M, Jacobowitz L. Medication Adherence Improvement Similar for Shared Decision-Making Preference or Longer PatientProvider Relationship. J Am Board Fam Med JABFM. 2018;31(5):752-760. doi:10.3122/jabfm.2018.05.180009

23. Kew KM, Malik P, Aniruddhan K, Normansell R. Shared decision-making for people with asthma. Cochrane Database Syst Rev. 2017;10:CD012330. doi:10.1002/14651858.CD012330.pub2 
24. Ben-Zacharia A, Adamson M, Boyd A, et al. Impact of Shared Decision Making on Disease-Modifying Drug Adherence in Multiple Sclerosis. Int J MS Care. 2018;20(6):287297. doi:10.7224/1537-2073.2017-070

25. Oh S-J, Ku JH, Lim SH, Jeon HG, Son H. Effect of a "centralized intensive education system" for clean intermittent self-catheterization in patients with voiding dysfunction who start catheterization for the first time. Int J Urol Off J Jpn Urol Assoc. 2006;13(7):905-909. doi:10.1111/j.1442-2042.2006.01438.x 